\title{
Current Status of Mucosal Imaging with Narrow-Band Imaging in the Esophagus
}

\author{
Keng Hoong Chiam¹, Seon Ho Shin ${ }^{1}$, Kun Cheong Choi ${ }^{1}$, Florencia Leiria ${ }^{1}$, Mariana Militz ${ }^{1}$, and Rajvinder Singh ${ }^{1,2}$ \\ ${ }^{1}$ Department of Gastroenterology, Lyell McEwin Hospital, Elizabeth Vale, and ${ }^{2}$ Faculty of Health and Medical Science, University of \\ Adelaide, Adelaide, Australia
}

Article Info

Received January 28, 2020

Revised March 3, 2020

Accepted March 4, 2020

Published online April 22, 2020

Corresponding Author

Rajvinder Singh

ORCID https://orcid.org/0000-0001-9116-6054

E-mail rajvinder.singh@sa.gov.au
Recent advances in endoscopic imaging of the esophagus have revolutionized the diagnostic capability for detecting premalignant changes and early esophageal malignancy. In this article, we review the practical application of narrow-band imaging focusing on diseases of the esophagus, including Barrett's esophagus, adenocarcinoma, and squamous cell carcinoma. (Gut Liver 2021;15:492-499)

Key Words: Barrett's esophagus; Esophageal adenocarcinoma; Esophageal squamous cell carcinoma; Narrow band imaging; Mucosal imaging

\section{INTRODUCTION}

Endoscopic imaging has evolved over time from white light endoscopy to the adoption of novel electronic imaging techniques utilizing the technology of altering whitelight with a push of a button. With the addition of magnification technology, the endoscopist now has the capability to assess mucosal surface architecture in greater detail. ${ }^{1}$ Narrow-band imaging (NBI) is an imaging technique that utilizes specific wavelength of blue and green light to penetrate into the superficial layers of the mucosa to highlight abnormal mucosal and vascular pattern. ${ }^{2}$ A white-light source filter located in front of a xenon arc lamp in the endoscope produces two selective narrow bands of wavelength lights measuring $415 \mathrm{~nm}$ and $540 \mathrm{~nm}$. The length of the wavelength is directly proportional to the depth of its penetration. The $415 \mathrm{~nm}$ wavelength highlights only the superficial mucosa where the capillaries appear brown whereas the $540 \mathrm{~nm}$ wavelength penetrates deeper into the lower parts of the mucosa and submucosa giving them a blue-green hue. ${ }^{2,3}$ The end result is the ability to better visualize the microsurface and microvascular patterns on the mucosal surface. ${ }^{4}$ This allows advanced evaluation of abnormal lesions such as dysplasia and cancer. ${ }^{5}$
BARRETT'S ESOPHAGUS AND ESOPHAGEAL ADENOCARCINOMA

Barrett's esophagus (BE) carries the risk of progression to esophageal adenocarcinoma (EAC). BE remains the sole proven premalignant condition for EAC. ${ }^{6}$ Treatment options are limited and prognosis remains bleak when EAC is diagnosed at a late stage. In order to achieve early diagnosis and treatment, national and international gastroenterological societies have endeavored to draft guidelines for $\mathrm{BE}$ surveillance. ${ }^{7}$ In general, the prevalence of $\mathrm{BE}$ has been estimated to be $1 \%-2 \%$ in patients receiving endoscopy for any indication and increases to $5 \%-15 \%$ among patients with symptoms of gastroesophageal reflux disease. ${ }^{8}$ Risk factors for developing BE include chronic gastroesophageal reflux disease, ${ }^{9,10}$ obesity (central adiposity), ${ }^{11,12}$ cigarette smoking, ${ }^{13}$ male sex, ${ }^{14}$ older age ${ }^{15}$ and a positive family history of BE or EAC. ${ }^{16}$

To diagnose $\mathrm{BE}$, two components need to be present: first, the endoscopic appearance of a salmon-pink colored columnar epithelium extending above the gastro-esophageal junction, replacing the normal tubular esophageal squamous epithelium and second, histological demonstration of esophageal columnar epithelium with intestinal metaplasia showing presence of mucin-containing goblet

Copyright $\odot$ Gut and Liver.

(c) (i) (S) This is an Open Access article distributed under the terms of the Creative Commons Attribution Non-Commercial License (http://creativecommons.org/licenses/by-nc/4.0) which permits unrestricted non-commercial use, distribution, and reproduction in any medium, provided the original work is properly cited. 
cells. ${ }^{17,18}$

To diagnose dysplasia, current guidelines recommend endoscopic surveillance by performing random four quadrant biopsies every 1 to $2 \mathrm{~cm}$ of the BE mucosa. ${ }^{19}$ However random sampling can lead to random errors where an area harboring dysplasia may be missed. ${ }^{20}$ Furthermore, once worrisome histology is found on random biopsies, it can be technically challenging to re-locate the lesion. Endoscopists adherence to biopsy guidelines is also low likely due to its cumbersome nature. ${ }^{21}$ Studies have shown that adherence to biopsy protocols worsen with increasing $\mathrm{BE}$ length and this becomes dangerous as the risk of EAC is greater with longer BE segments. ${ }^{21-23}$

The rationale behind the advent of NBI is to complement and improve observation methods and possibly reduce the need for random histological sampling as suspicious areas may be identified and interrogated further. There have been various attempts to describe pit patterns seen in $\mathrm{BE}^{24,25} \mathrm{~A}$ formal consensus is required to limit the varying classifications put out by different groups of experts as it only confuses gastroenterologists adopting the utility of NBI.

\section{NBI OF BARRETT'S ESOPHAGUS}

It has been shown that targeted biopsies with NBI assistance can achieve the equivalent of random biopsies using high definition white light endoscopy (WLE) in the detection of intestinal metaplasia with lesser number of biopsies and better diagnostic yield. ${ }^{26}$ The additional employment of high magnification settings significantly increased the accuracy of cancer detection compared to NBI alone..$^{27,28}$ This combination allows the operator the capability to zoom in and focus on an area of interest, thus allowing confirmation of findings when evaluating dysplastic areas. The rapid evolution of NBI with magnification endoscopy assessment of $\mathrm{BE}$ is as a result of its excellent correlation with histological outcome. ${ }^{29}$ This obviates the need for physical biopsy when optical biopsy with NBI and magnification can confidently confirm non-dysplastic areas. ${ }^{30}$

Sharma et al. ${ }^{24}$ from Kansas and Kara et al. ${ }^{5}$ from Amsterdam were amongst the first to describe and characterize certain mucosal and vascular patterns observed on NBI magnification images that correlated with non-dysplastic and dysplastic Barrett's mucosa. The basis of these classifications work on the observations that non-dysplastic Barrett's mucosa has regular mucosal and vascular pattern while advance dysplastic lesions has irregular, distorted or absent mucosal and vascular pattern.

Sharma's group was able to identify that irregular and distorted mucosal pattern with abnormal branching, tortuous or non-uniform vascular pattern had $100 \%$ sensitivity and $95 \%$ positive predictive value of identifying high grade dysplasia. ${ }^{24}$ Of note, NBI magnification imaging was not reliable in detecting low grade dysplasia. Kara et al. ${ }^{5}$ were first to compare NBI's practical superiority over chromoendoscopy. They further proposed a classification system based on NBI morphological appearance of the mucosal and vascular pattern. The emphasis was again on regularity of different mucosal patterns such as villous or gyrus pattern, regularity of vascular pattern and absence of any abnormal appearing vessels which was most consistent with non-dysplastic tissue. Presence of any one criteria such as irregularity in mucosal pattern, vascular pattern or abnormal vessel would significantly increase the probability of higher grade dysplasia; up to $85 \%$ probability if two features were present. Absence of any of these criteria had high negative predictive probability for dysplasia.

Subsequently, a more refined but complex combination of five different fine mucosal patterns (FMP) and capillary patterns $(\mathrm{CP})$ classification was put forth by Goda et al..$^{31}$ from Tokyo to describe various appearances that is predictive for detecting specialized intestinal mucosa and superficial Barrett's adenocarcinoma. Of all patterns, a cerebriform FMP and ivy-like or DNA-spiral like appearance of $\mathrm{CP}$ most predicted specialized intestinal mucosa. The cerebriform FMP pattern consists of complicated branching and unions. As for the ivy-like or DNA-spiral like appearance of CP, it involves spirals and complicated branching with adjacent capillaries showing interconnections resembling a chain or net. In their cohort, all cases of superficial or intramucosal adenocarcinoma (which in Western countries may have been termed high-grade dysplasia) demonstrated both irregular FMP and CP with 100\% sensitivity and specificity. Irregular FMP is characterized by irregularity in shape and branching in mucosal pattern and irregular CP is characterized as irregular micro-vessels with irregular course and uneven forms.

In order to provide a practical NBI method to identify dysplastic lesions, a more simplified classification by Singh et al. ${ }^{25}$ was described by combining the pit patterns of the mucosal surface and the regularity of the microvasculature in four easily distinguishable types (Table 1).

Type A mucosa was indicative of columnar mucosa without intestinal metaplasia with positive predictive value of $100 \%$. Type B and C were typical of intestinal metaplasia with positive predictive value of $90 \%$. Type $\mathrm{D}$ was indicated of high grade dysplasia with $79 \%$ positive predictive value and more importantly $100 \%$ negative predictive value. It is also important to note that all of the above classifications with NBI patterns were unable to predict low grade dyspla- 
sia with confidence.

Singh et al. ${ }^{32}$ further simplified the classification system in 2014 where the microstructural pattern and microvascular architecture were classified into three subtypes (Table 2). Type 1 was characterized by regular pits and/or vasculature (Figs 1-3) including absent/round/oval/linear/ cerebriform/villous pits with regular vasculature. Type 2 was characterized by irregular/absent pits and irregular vasculature (Fig. 4) and type 3 has equivocal features which may exhibit dilated vasculature but no change in caliber (Fig. 5). The performance of this classification to identify high grade dysplasia was tested in the Asia-Pacific Barrett's Consortium in 2014 involving endoscopists from 11 countries with varying experience from the Asia-Pacific region. They evaluated images of $\mathrm{BE}$ with dysplastic and non-dysplastic areas.

The results were affirmative for positive identification of high grade dysplastic BE areas with sensitivity of $90 \%$ and

Table 1. Nottingham Classification for Esophageal Adenocarcinoma

\begin{tabular}{ccc}
\hline Type & Description & Histology \\
\hline A & Round pits with regular microvasculature & Columnar mucosa \\
B & Villous/ridge pits with regular microvascu- & Intestinal metaplasia \\
& lature & \\
C & Absent pits with regular microvasculature & Intestinal metaplasia \\
D & Distorted pits with irregular microvascula- & High grade dysplasia \\
& ture
\end{tabular}

Table 2. Asia-Pacific Barrett's Consortium Classification

\begin{tabular}{ccl}
\hline Type & \multicolumn{1}{c}{ Description } & \multicolumn{1}{c}{ Histology } \\
\hline 1 & Regular pits and/or vasculature & No dysplasia \\
2 & $\begin{array}{c}\text { Irregular/absent pits and irregular vascu- } \\
\text { lature }\end{array}$ & High grade dysplasia \\
3 & $\begin{array}{c}\text { Equivocal, area may exhibit dilated vascu- } \\
\text { lature but no change in caliber }\end{array}$ & Not clear/unsure \\
& & \\
\hline
\end{tabular}

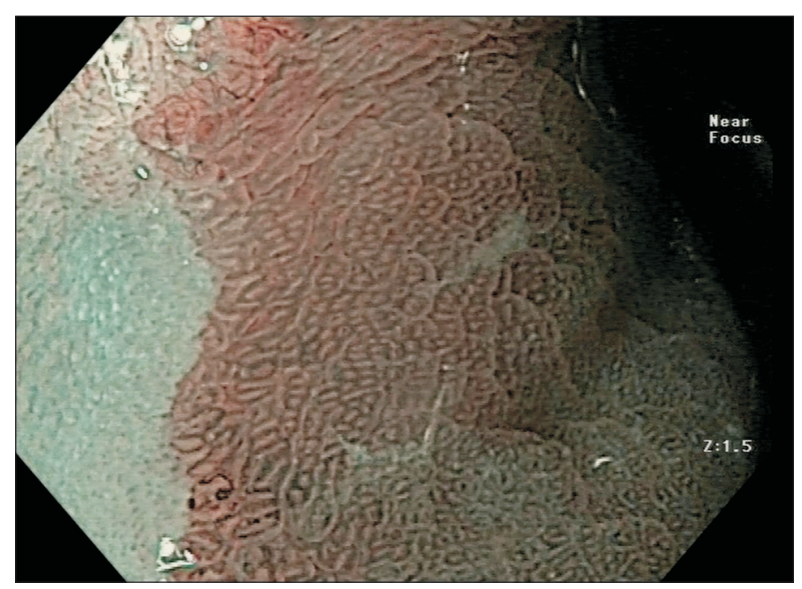

Fig. 1. Round pits and regular microvasculature (no dysplasia). negative predictive value of $99 \%$ showing that such a classification could be readily adopted. ${ }^{32}$

\section{ESOPHAGEAL SQUAMOUS CELL CARCINOMA}

Esophageal squamous cell carcinoma (ESCC) remains at present the dominant histology of esophageal cancer worldwide. ${ }^{33}$ ESCC appears to be more prevalent in countries stretching from northeast China to the Middle East forming what is termed, the high risk "Asian esophageal cancer belt. ${ }^{34}$ It is 2 to 4 times more frequent in males. ${ }^{35}$ Risk factors for the development of ESCC include smoking and alcohol consumption. Smoking increases the risk of developing ESCC by 5 -fold. ${ }^{36}$ The reported odds are also greater for former smokers when compared to those who

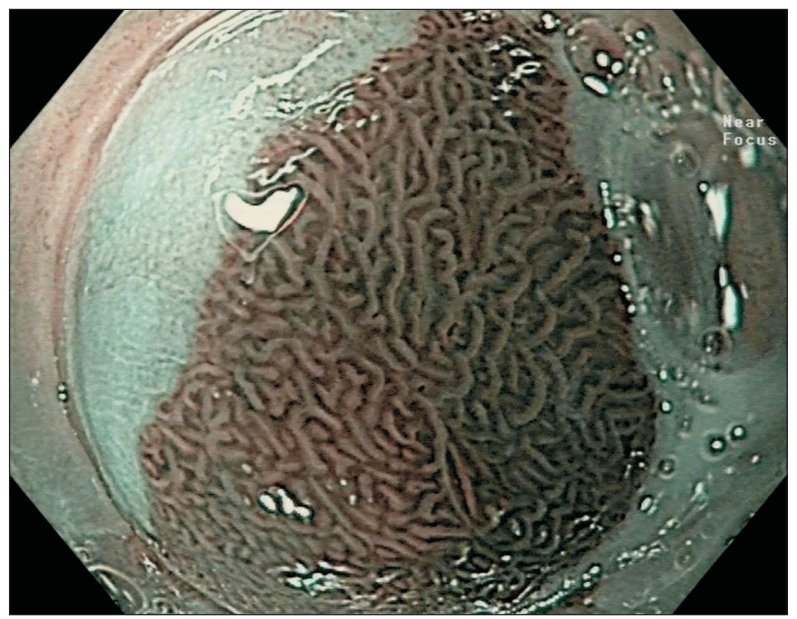

Fig. 2. Ridged/villous pits and regular microvasculature (no dysplasia).

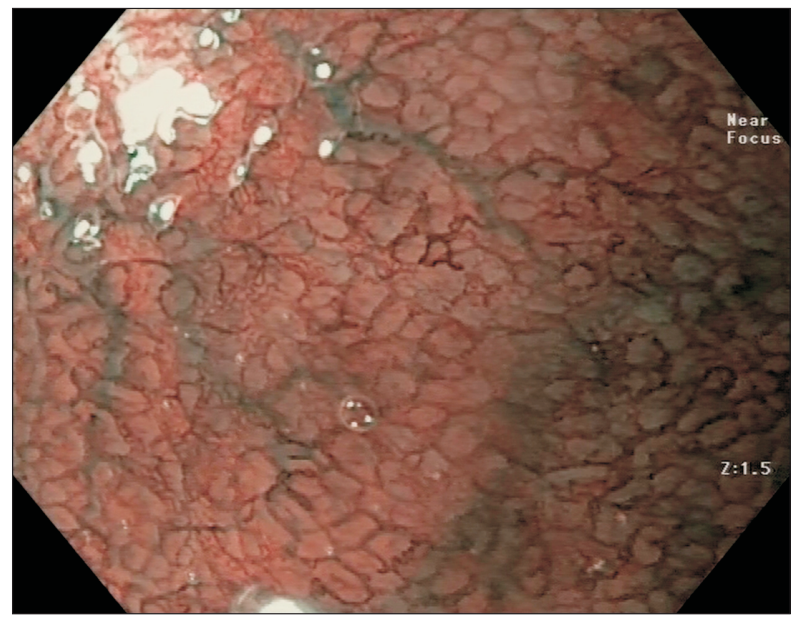

Fig. 3. Absent pits and regular microvasculature (no dysplasia). 


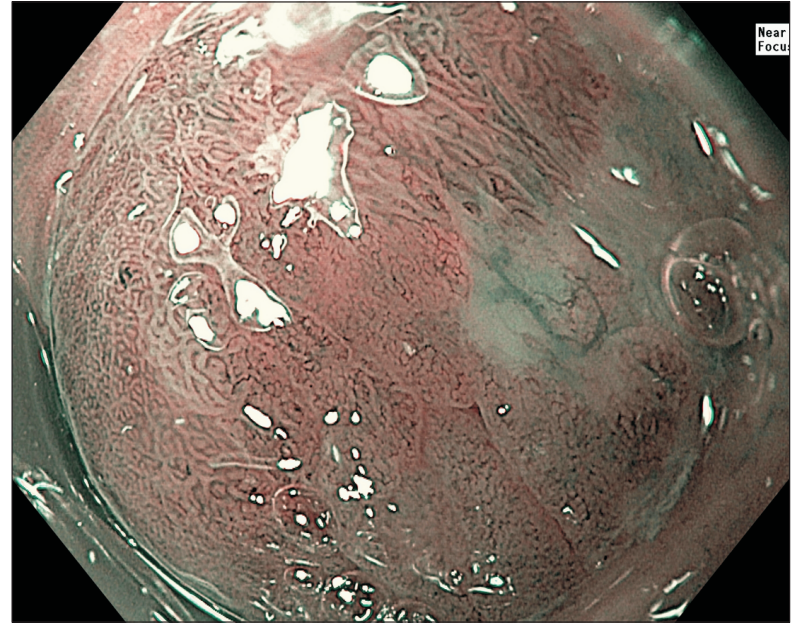

Fig. 4. Irregular/absent pits and irregular microvasculature (highgrade dysplasial.

never smoked. With alcohol, the inherited enzyme deficiency of aldehyde dehydrogenase 2 which is involved in alcohol metabolism has been associated with increased risk of ESCC. ${ }^{37}$ It was reported that an estimated $36 \%$ of East Asians (Japanese, Chinese, and Koreans) are deficient in this enzyme leading to the "Asian Flush or Glow" response characterized by symptoms of facial flushing, nausea and tachycardia after alcohol consumption.$^{38}$ Other risk factors include dietary aspects such as the consumption of food with high concentration of nitrogenous compounds, ${ }^{36}$ hot beverages like coffee, tea and mate (caffeine-rich infused drink $)^{39}$ and genetic related etiologies such as tylosis. ${ }^{40}$

It is well known from epidemiologic studies that ESCC risk factors differ from geographical regions and ethnicity making the implementation of a uniformed screening program challenging. ${ }^{34-36}$ Additionally, early diagnosis without a screening program is not possible given that most patients remain asymptomatic. Therefore, certain communities and countries provide a tailored approach focused heavily on the community who are at risk. This has been performed in China where endoscopic screening is employed to detect dysplastic lesions in high-risk asymptomatic patients. ${ }^{41}$ The risk of developing ESCC not surprisingly is strongly associated with increasing grades of dysplasia (relative risk, 15.3 to 52.4 for severe dysplasia) and carcinoma in situ (relative risk, 16.6 to 71.4 ). ${ }^{42}$

\section{NBI OF SQUAMOUS CELL CARCINOMA}

Unlike gastric, intestinal, colonic or Barrett's mucosa, squamous epithelium lacks mucosal contours where "disturbances" in pit patterns can be visualized. Hence NBI's ability to provide high contrast images of the microvascular

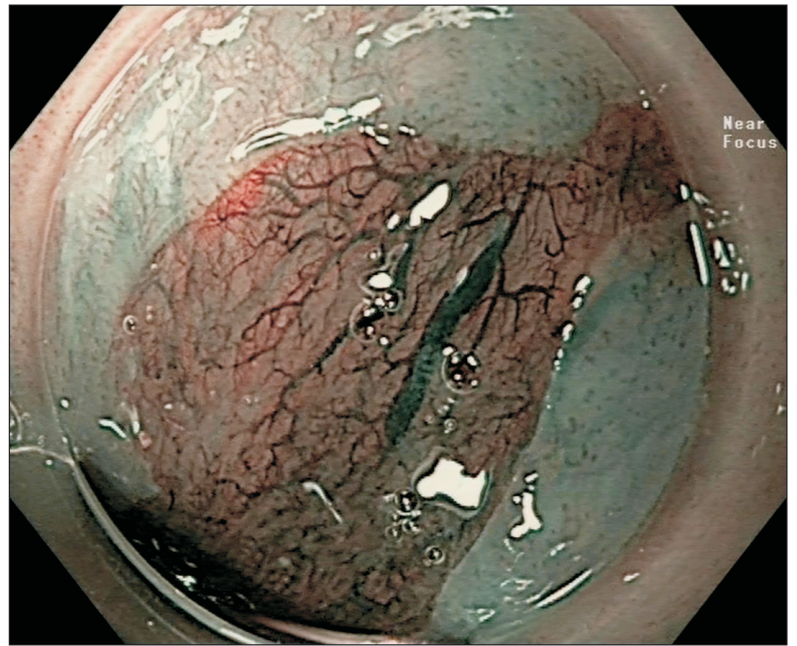

Fig. 5. Dilated vasculature but no change in caliber (equivocal).

structure plays a key role in describing ESCC at different stages. Numerous studies to date have identified and characterized the intrapapillary capillary loops (IPCL) patterns as major determinants of early ESCC characteristics. This remarkable observation was spearheaded by Inoue and colleagues where a classification of IPCL patterns identified by NBI with magnification was developed to correlate with the intraepithelial neoplastic changes and the depth of invasion. ${ }^{43-45}$ The progressive abnormal changes of IPCL patterns include the degree of dilatation, tortuosity, caliber and variation in shapes. Such progressive abnormal changes allow the endoscopist to predict the degree of neoplasia, its invasion depth and allows determination of the feasibility of endoscopic resection as a curative procedure. ${ }^{45-47}$

In normal mucosa, IPCL arises perpendicularly or vertically in thin loop like structures. With reflux esophagitis, the IPCL pattern may become slightly more elongated and dilated. In the presence of tissue atypia or dysplastic changes, the IPCL becomes remarkably dilated with irregularity of the vessel caliber. There is non-uniformity between each IPCL as it progresses towards higher degree of dysplasia and early invasive cancer involving up to the lamina propria. With deeper tissue invasion into muscularis mucosa, the IPCL structure is then destroyed, losing its loop like appearance. They become highly irregular; giving them a thin tree-branch like shape that spreads horizontally instead of arising vertically. Once the tumor invades into the submucosa, one could observe thick bluish to greenish large vessels forming. ${ }^{43,46}$ Arima et al. ${ }^{47}$ described the "avascularity concept" when ESCC progresses towards the submucosa; the tumor demonstrates thickened avascular areas. The size of this avascular area also directly correlates with invasion depth. ESCCs invading muscularis mucosa and up to $200 \mu \mathrm{m}$ of submucosa showed a mean avascular 
area of $2.5 \mathrm{~mm}$ compared to ESCCs invading deeper than $200 \mu \mathrm{m}$ into submucosa which showed a mean avascular area of $9 \mathrm{~mm}$.

Goda et al. ${ }^{48}$ demonstrated non-inferior diagnostic potential of magnifying endoscopy with NBI when compared to non-magnifying high-resolution WLE and highfrequency endoscopic ultrasonography with no significant difference in sensitivity and specificity. In comparison, NBI with magnification also reduced invasion depth overestimation translating to the right therapeutic intervention which has significant implications on morbidity and mortality.

Aside from observing IPCL patterns, Ishihara and colleagues made observations of brownish dots and epithelial appearance on NBI as another feature associated with high grade intraepithelial neoplasia or invasive cancer. ${ }^{49}$ Analysis into these findings were investigated and reproduced in a study by Kanzaki et al..$^{50}$ where brownish epithelium were confirmed to be significantly associated with high grade intraepithelial neoplasia and ESCC. ${ }^{50}$ The appearance of brown colored neoplastic area was as a result of epithelial and keratinous layer thinning due to the neoplastic process. This inspired a retrospective observation which validated the usefulness and ease of NBI over WLE in detecting superficial esophageal neoplasia $(<10 \mathrm{~mm}$ diameter lesions) with brownish dots and epithelium. ${ }^{51}$ The potential of NBI in highlighting superficial cancers continues to be recognized over conventional WLE and chromoendoscopy with Lugol's iodine. ${ }^{52,53}$ The chances of overlooking suspicious lesions could certainly be minimized by the supplemental utility of NBI given the astounding report that as high as $7.8 \%$ of esophageal cancer lesions were missed in the United Kingdom. These were patients had an endoscopy done 3 to 36 months preceding diagnosis. ${ }^{54}$

In regards to the usefulness of NBI in assessing depth of

Table 3. AB Classification for Esophageal SCC

\begin{tabular}{|c|c|c|}
\hline $\begin{array}{l}\text { Vessel } \\
\text { type }\end{array}$ & Definition & Invasion depth \\
\hline A & $\begin{array}{l}\text { Normal or abnormal IPCL without } \\
\text { severe irregularity }\end{array}$ & Noninvasive \\
\hline B1 & $\begin{array}{l}\text { Severe irregularity/dilatation of IPCL } \\
\text { with loop-like formation }\end{array}$ & $\begin{array}{l}\text { High grade intraepi- } \\
\text { thelial neoplasia } \\
\text { or SCC limited to } \\
\text { lamina propria }\end{array}$ \\
\hline B2 & $\begin{array}{l}\text { Severe irregularity/dilatation of IPCL } \\
\text { with loss of loop-like formation }\end{array}$ & $\begin{array}{l}\text { SCC Involving mus- } \\
\text { cularis mucosa } \\
\text { and }<200 \mu \mathrm{m} \text { depth } \\
\text { of submucosa }\end{array}$ \\
\hline B3 & $\begin{array}{l}\text { Highly dilated irregular vessels more } \\
\text { than } 3 \text { times B2 vessel }\end{array}$ & $\begin{array}{l}>200 \mu \mathrm{m} \text { depth of } \\
\text { submucosal inva- } \\
\text { sion }\end{array}$ \\
\hline
\end{tabular}

SCC, squamous cell carcinoma; IPCL, intrapapillary capillary loop. invasion for superficial ESCC, there was a conflicting multicenter prospective study published in 2015 by Ebi et al. ${ }^{55}$ It reported that magnifying endoscopy with NBI to be not superior to conventional endoscopy in assessing the depth of invasion of superficial ESCC. The authors reported accuracy of magnifying endoscopy with NBI $(65.3 \%)$ versus accuracy of conventional endoscopy $(71.4 \%, \mathrm{p}=0.375)$. However, this study had a relatively small sample size involving 49 lesions. The result comparing the accuracy between magnifying endoscopy with NBI and conventional endoscopy with a p-value of 0.375 was not statistically significant.

In 2017, another prospective multicenter study using magnifying endoscopic NBI (ME-NBI) in predicting the invasion depth of superficial squamous cell carcinoma was published by Oyama et al. ${ }^{56}$ The study involved 211 patients with superficial ESCC. The study found that MENBI had an overall accuracy rate of $90.5 \%$ for predicting cancer invasion depth based on type B1, B2 and B3 microvessels pattern. The authors concluded that ME-NBI is of sufficient high accuracy for clinical use.

The study by Oyama et $a{ }^{56}{ }^{56}$ was based on the recently revised 2017 Japan Esophageal Society guideline classifying superficial ESCC with magnifying endoscopy and NBI. This was a simplified classification proposed for estimating the depth of invasion of superficial ESCC by observing the microvascular patterns. The $\mathrm{AB}$ classification (Table 3 and Figs 6-9) is composed of two types of vessels with type A vessels (lacking severe irregularity) indicating non-cancer subtype while type $B$ vessels are related to cancer.

Type B microvessels are sub-classified further into three groups, B1, B2 and B3. B1 predicts invasion depth confined within the epithelium or lamina propria where endoscopic resection is still feasible. B2 however suggests invasion into muscularis mucosa or beyond to the superficial layers of submucosa where endoscopic resection could still be a

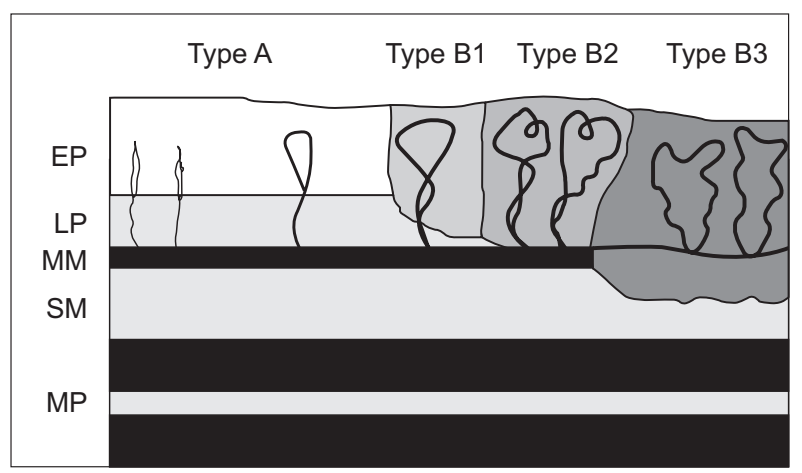

Fig. 6. Diagram showing invasion depth according to different types of intrapapillary capillary loop patterns.

$E P$, epithelium; LP, lamina propria; MM, muscularis mucosa; SM, submucosa; MP, muscularis propria. 


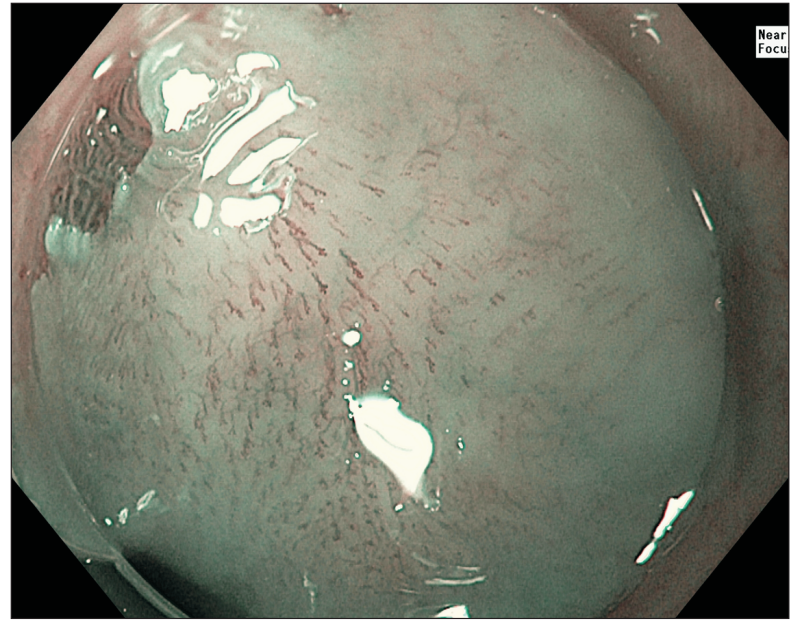

Fig. 7. Type A microvessels without severe irregularity-these findings are indicative of normal, inflammatory or low-grade intraepithelial neoplasia.

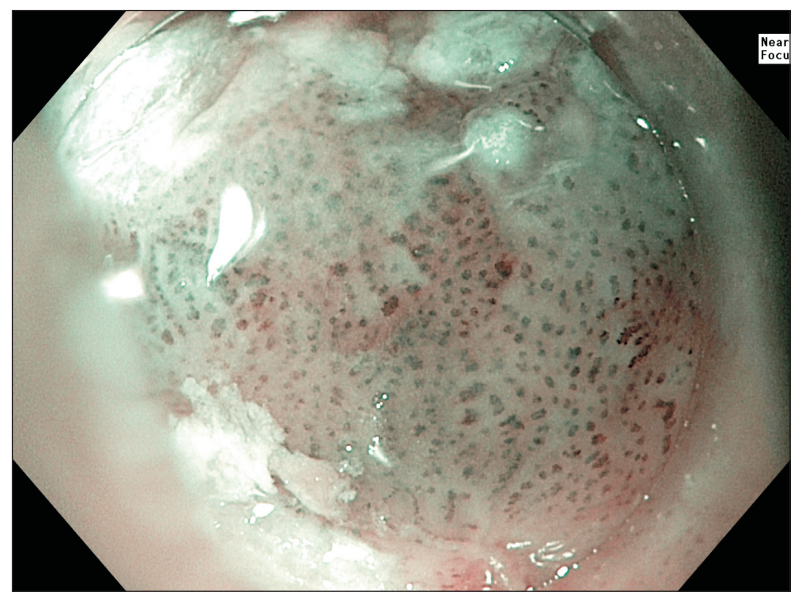

Fig. 8. Type B1 microvessels with severe irregularity but with a closed loop formation-these findings are consistent with high-grade intraepithelial neoplasia or squamous cell carcinoma limited to the lamina propria.

relative indication. B3 subtype marks the contraindication for endoscopic resection as it traverses more than $200 \mu \mathrm{m}$ into the submucosa where risks of lymphovascular invasion increases exponentially. ${ }^{56}$

\section{CONCLUDING REMARKS}

The role of NBI in the esophagus continues to impact major clinical decision in early cancer management. Its effectiveness in terms of ease of use, high sensitivity and accuracy has been proven. However, the interpretation of mucosal surface and microvasculature pattern requires training. Classifications have been revised to encourage

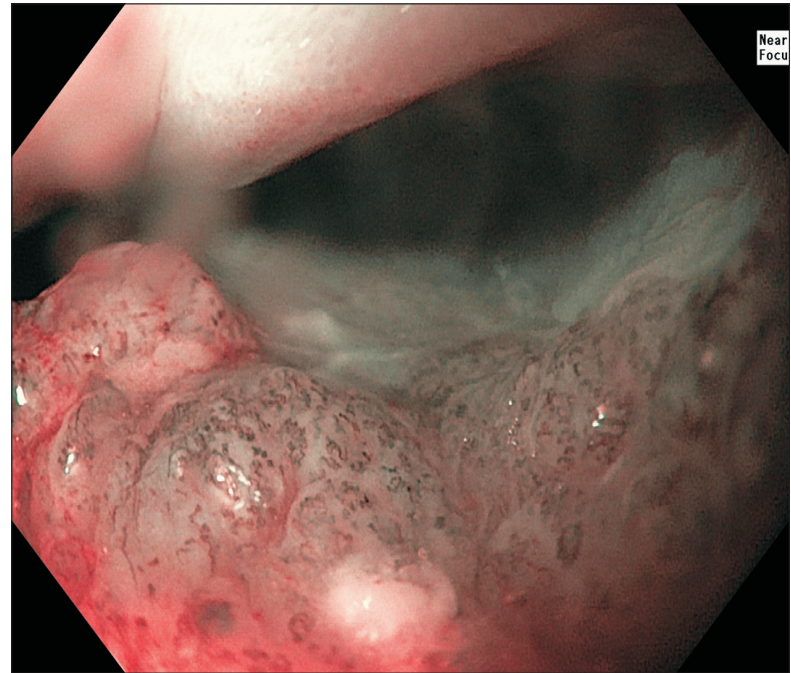

Fig. 9. Type B2 microvessels with severe irregularity without a looplike formation indicative of invasive cancer beyond but limited to less than $200 \mu \mathrm{m}$ of the submucosa.

uniformity and simplify ease of learning. As a recommendation, the simplified Asia-Pacific Barrett's Consortium Classification for $\mathrm{BE}$ and the $\mathrm{AB}$ classification by Japanese Esophageal Society for ESCC could be adopted.

\section{CONFLICTS OF INTEREST}

No potential conflict of interest relevant to this article was reported.

\section{ORCID}

Keng Hoong Chiam

https://orcid.org/0000-0002-8150-6286

Seon Ho Shin https://orcid.org/0000-0002-4840-2709 Kun Cheong Choi https://orcid.org/0000-0001-7470-3591 Florencia Leiria https://orcid.org/0000-0002-7846-2884 Mariana Militz https://orcid.org/0000-0002-0095-845X Rajvinder Singh https://orcid.org/0000-0001-9116-6054

\section{REFERENCES}

1. Banerjee R, Reddy N. A primer on narrow band imaging. Hyderabad: Paras Publishing, 2009.

2. Mangira D, Wong S, Sharma P, Singh R. Virtual chromoendoscopy. In: Konda VJA, Waxman I, eds. Endoscopic imaging techniques and tools. 1st ed. Basel: Springer, 2016:49-60.

3. Kuznetsov K, Lambert R, Rey JF. Narrow-band imaging: po- 
tential and limitations. Endoscopy 2006;38:76-81.

4. Gono K, Obi T, Yamaguchi M, et al. Appearance of enhanced tissue features in narrow-band endoscopic imaging. J Biomed Opt 2004;9:568-577.

5. Kara MA, Ennahachi M, Fockens P, ten Kate FJ, Bergman JJ. Detection and classification of the mucosal and vascular patterns (mucosal morphology) in Barrett's esophagus by using narrow band imaging. Gastrointest Endosc 2006;64:155-166.

6. Hameeteman W, Tytgat GN, Houthoff HJ, van den Tweel JG. Barrett's esophagus: development of dysplasia and adenocarcinoma. Gastroenterology 1989;96(5 Pt 1):1249-1256.

7. Amadi C, Gatenby P. Barrett's oesophagus: current controversies. World J Gastroenterol 2017;23:5051-5067.

8. Runge TM, Abrams JA, Shaheen NJ. Epidemiology of Barrett's esophagus and esophageal adenocarcinoma. Gastroenterol Clin North Am 2015;44:203-231.

9. Zagari RM, Fuccio L, Wallander MA, et al. Gastro-oesophageal reflux symptoms, oesophagitis and Barrett's oesophagus in the general population: the Loiano-Monghidoro study. Gut 2008;57:1354-1359.

10. Taylor JB, Rubenstein JH. Meta-analyses of the effect of symptoms of gastroesophageal reflux on the risk of Barrett's esophagus. Am J Gastroenterol 2010;105:1729-1737.

11. Kubo A, Cook MB, Shaheen NJ, et al. Sex-specific associations between body mass index, waist circumference and the risk of Barrett's oesophagus: a pooled analysis from the international BEACON consortium. Gut 2013;62:1684-1691.

12. Singh S, Sharma AN, Murad MH, et al. Central adiposity is associated with increased risk of esophageal inflammation, metaplasia, and adenocarcinoma: a systematic review and meta-analysis. Clin Gastroenterol Hepatol 2013;11:13991412.

13. Andrici J, Cox MR, Eslick GD. Cigarette smoking and the risk of Barrett's esophagus: a systematic review and metaanalysis. J Gastroenterol Hepatol 2013;28:1258-1273.

14. Cook MB, Wild CP, Forman D. A systematic review and meta-analysis of the sex ratio for Barrett's esophagus, erosive reflux disease, and nonerosive reflux disease. Am J Epidemiol 2005;162:1050-1061.

15. Edelstein ZR, Bronner MP, Rosen SN, Vaughan TL. Risk factors for Barrett's esophagus among patients with gastroesophageal reflux disease: a community clinic-based casecontrol study. Am J Gastroenterol 2009;104:834-842.

16. Chak A, Lee T, Kinnard MF, et al. Familial aggregation of Barrett's oesophagus, oesophageal adenocarcinoma, and oesophagogastric junctional adenocarcinoma in Caucasian adults. Gut 2002;51:323-328.

17. Whiteman DC, Appleyard M, Bahin FF, et al. Australian clinical practice guidelines for the diagnosis and management of Barrett's esophagus and early esophageal adenocarcinoma. J Gastroenterol Hepatol 2015;30:804-820.
18. Shaheen NJ, Falk GW, Iyer PG, Gerson LB; American College of Gastroenterology. ACG clinical guideline: diagnosis and management of Barrett's esophagus. Am J Gastroenterol 2016;111:30-50.

19. American Gastroenterological Association, Spechler SJ, Sharma P, Souza RF, Inadomi JM, Shaheen NJ. American Gastroenterological Association medical position statement on the management of Barrett's esophagus. Gastroenterology 2011;140:1084-1091.

20. Falk GW, Rice TW, Goldblum JR, Richter JE. Jumbo biopsy forceps protocol still misses unsuspected cancer in Barrett's esophagus with high-grade dysplasia. Gastrointest Endosc 1999;49:170-176.

21. Abrams JA, Kapel RC, Lindberg GM, et al. Adherence to biopsy guidelines for Barrett's esophagus surveillance in the community setting in the United States. Clin Gastroenterol Hepatol 2009;7:736-742.

22. Weston AP, Badr AS, Hassanein RS. Prospective multivariate analysis of clinical, endoscopic, and histological factors predictive of the development of Barrett's multifocal high-grade dysplasia or adenocarcinoma. Am J Gastroenterol 1999;94: 3413-3419.

23. Weston AP, Krmpotich PT, Cherian R, Dixon A, Topalosvki M. Prospective long-term endoscopic and histological follow-up of short segment Barrett's esophagus: comparison with traditional long segment Barrett's esophagus. Am J Gastroenterol. 1997;92:407-413.

24. Sharma P, Bansal A, Mathur S, et al. The utility of a novel narrow band imaging endoscopy system in patients with Barrett's esophagus. Gastrointest Endosc 2006;64:167-175.

25. Singh R, Anagnostopoulos GK, Yao K, et al. Narrow-band imaging with magnification in Barrett's esophagus: validation of a simplified grading system of mucosal morphology patterns against histology. Endoscopy 2008;40:457-463.

26. Sharma P, Hawes RH, Bansal A, et al. Standard endoscopy with random biopsies versus narrow band imaging targeted biopsies in Barrett's oesophagus: a prospective, international, randomised controlled trial. Gut 2013;62:15-21.

27. Lee CT, Chang CY, Lee YC, et al. Narrow-band imaging with magnifying endoscopy for the screening of esophageal cancer in patients with primary head and neck cancers. Endoscopy 2010;42:613-619.

28. Lee YC, Wang CP, Chen CC, et al. Transnasal endoscopy with narrow-band imaging and Lugol staining to screen patients with head and neck cancer whose condition limits oral intubation with standard endoscope (with video). Gastrointest Endosc 2009;69(3 Pt 1):408-417.

29. Hamamoto Y, Endo T, Nosho K, Arimura Y, Sato M, Imai K. Usefulness of narrow-band imaging endoscopy for diagnosis of Barrett's esophagus. J Gastroenterol 2004;39:14-20.

30. Singh R, Shahzad MA, Tam W, et al. Preliminary feasibility 
study using a novel narrow-band imaging system with dual focus magnification capability in Barrett's esophagus: is the time ripe to abandon random biopsies? Dig Endosc 2013;25 Suppl 2:151-156.

31. Goda K, Tajiri H, Ikegami M, Urashima M, Nakayoshi T, Kaise M. Usefulness of magnifying endoscopy with narrow band imaging for the detection of specialized intestinal metaplasia in columnar-lined esophagus and Barrett's adenocarcinoma. Gastrointest Endosc 2007;65:36-46.

32. Singh R, Jayanna M, Wong J, et al. Narrow-band imaging and white-light endoscopy with optical magnification in the diagnosis of dysplasia in Barrett's esophagus: results of the Asia-Pacific Barrett's Consortium. Endosc Int Open 2015;3: E14-E18.

33. Pennathur A, Gibson MK, Jobe BA, Luketich JD. Oesophageal carcinoma. Lancet 2013;381:400-412.

34. Zhang Y. Epidemiology of esophageal cancer. World J Gastroenterol 2013;19:5598-5606.

35. Zhang HZ, Jin GF, Shen HB. Epidemiologic differences in esophageal cancer between Asian and Western populations. Chin J Cancer 2012;31:281-286.

36. Wheeler JB, Reed CE. Epidemiology of esophageal cancer. Surg Clin North Am 2012;92:1077-1087.

37. Brooks PJ, Enoch MA, Goldman D, Li TK, Yokoyama A. The alcohol flushing response: an unrecognized risk factor for esophageal cancer from alcohol consumption: version 2 . PLoS Med 2009;6:e50.

38. Eng MY, Luczak SE, Wall TL. ALDH2, ADH1B, and ADH1C genotypes in Asians: a literature review. Alcohol Res Health 2007;30:22-27.

39. Islami F, Boffetta P, Ren JS, Pedoeim L, Khatib D, Kamangar F. High-temperature beverages and foods and esophageal cancer risk: a systematic review. Int J Cancer 2009;125:491524.

40. Ellis A, Risk JM, Maruthappu T, Kelsell DP. Tylosis with oesophageal cancer: diagnosis, management and molecular mechanisms. Orphanet J Rare Dis 2015;10:126.

41. Lin Y, Totsuka Y, He Y, et al. Epidemiology of esophageal cancer in Japan and China. J Epidemiol 2013;23:233-242.

42. Wang GQ, Abnet CC, Shen Q, et al. Histological precursors of oesophageal squamous cell carcinoma: results from a 13 year prospective follow up study in a high risk population. Gut 2005;54:187-192.

43. Inoue H, Kaga M, Ikeda $H$, et al. Magnification endoscopy in esophageal squamous cell carcinoma: a review of the intrapapillary capillary loop classification. Ann Gastroenterol 2015;28:41-48.

44. Sato $H$, Inoue $H$, Ikeda $H$, et al. Utility of intrapapillary capillary loops seen on magnifying narrow-band imaging in estimating invasive depth of esophageal squamous cell carcinoma. Endoscopy 2015;47:122-128.

45. Santi EG, Inoue $\mathrm{H}$, Ikeda $\mathrm{H}$, et al. Microvascular caliber changes in intramucosal and submucosally invasive esophageal cancer. Endoscopy 2013;45:585-588.

46. Singh R, Lee SY, Vijay N, Sharma P, Uedo N. Update on narrow band imaging in disorders of the upper gastrointestinal tract. Dig Endosc 2014;26:144-153.

47. Arima M, Tada M, Arima H. Evaluation of microvascular patterns of superficial esophageal cancers by magnifying endoscopy. Esophagus 2005;2:191-197.

48. Goda K, Tajiri H, Ikegami M, et al. Magnifying endoscopy with narrow band imaging for predicting the invasion depth of superficial esophageal squamous cell carcinoma. Dis Esophagus 2009;22:453-460.

49. Ishihara R, Inoue T, Uedo N, et al. Significance of each narrow-band imaging finding in diagnosing squamous mucosal high-grade neoplasia of the esophagus. J Gastroenterol Hepatol 2010;25:1410-1415.

50. Kanzaki H, Ishihara R, Ishiguro S, et al. Histological features responsible for brownish epithelium in squamous neoplasia of the esophagus by narrow band imaging. J Gastroenterol Hepatol 2013;28:274-278.

51. Mochizuki Y, Saito Y, Kobori A, et al. Magnified endoscopy combined with narrow band imaging of minimal superficial esophageal neoplasia: indicators to differentiate intraepithelial neoplasias. J Gastrointest Cancer 2012;43:599-606.

52. Muto M, Minashi K, Yano T, et al. Early detection of superficial squamous cell carcinoma in the head and neck region and esophagus by narrow band imaging: a multicenter randomized controlled trial. J Clin Oncol 2010;28:1566-1572.

53. Kuraoka K, Hoshino E, Tsuchida T, Fujisaki J, Takahashi H, Fujita R. Early esophageal cancer can be detected by screening endoscopy assisted with narrow-band imaging (NBI). Hepatogastroenterology 2009;56:63-66.

54. Chadwick G, Groene O, Hoare J, et al. A population-based, retrospective, cohort study of esophageal cancer missed at endoscopy. Endoscopy 2014;46:553-560.

55. Ebi M, Shimura T, Yamada T, et al. Multicenter, prospective trial of white-light imaging alone versus white-light imaging followed by magnifying endoscopy with narrow-band imaging for the real-time imaging and diagnosis of invasion depth in superficial esophageal squamous cell carcinoma. Gastrointest Endosc 2015;81:1355-1361.

56. Oyama T, Inoue $\mathrm{H}$, Arima $\mathrm{M}$, et al. Prediction of the invasion depth of superficial squamous cell carcinoma based on microvessel morphology: magnifying endoscopic classification of the Japan Esophageal Society. Esophagus 2017;14: 105-112. 